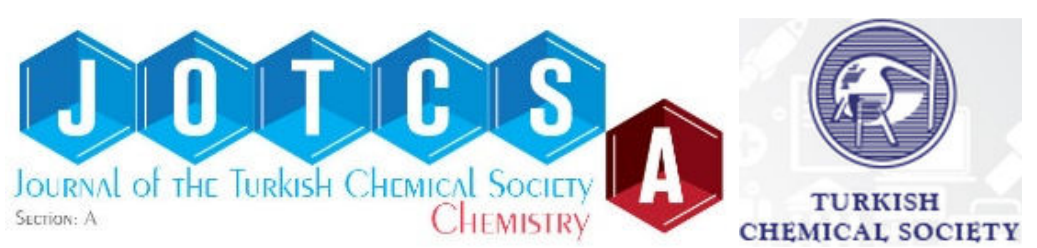

\title{
Chemical investigation and antioxidant activity of fractions of Lannea humilis (Oliv.) Engl.
}

\author{
ACHIKA Jonathan Ilemona, AYO Racheal Gbekele-Oluwa, OYEWALE Adebayo Ojo, and \\ JAMES Dama Habila \\ Department of Chemistry, Ahmadu Bello University, Zaria. Kaduna State, Nigeria.
}

\begin{abstract}
The aim of this experiment was to establish the phytochemical constitution and antioxidant activity of the fractions of Lannea humilis. Chemical investigation and antioxidant activity of the fractions were carried out using standard methods. Steroids and terpenes were available in the hexane, ethyl acetate, and methanol fractions, while tannins, flavonoids and alkaloids were available in the ethyl acetate and methanol extracts. Carbohydrate and saponins were available in the methanol fraction. The antioxidant activity of this plant extracts demonstrated a dose-dependent increment. The ethyl acetate extract displayed most noteworthy antioxidant activity of $98 \%$ at $240 \mu \mathrm{g} \cdot \mathrm{mL}^{-1}$, followed by the hexane extract which had a percentage antioxidant activity of $92 \%$ at $240 \mu \mathrm{g} \cdot \mathrm{mL}^{-1}$. The methanol extract demonstrated percentage antioxidant activity of $71 \%$ at $240 \mu \mathrm{g} \cdot \mathrm{mL}^{-1}$. This result shows that this plant can be used as a good antioxidant. These observations demonstrated that this plant has antioxidant activity and consequently can be used as an antioxidant agent.
\end{abstract}

Keywords: Antioxidant activity; 2,2-diphenyl-1-picrylhydrazyl; phenolic compounds; antioxidant activity; Lannea humilis.

Cite this: Ilemona AJ, Gbekele-Oluwa AR, Ojo OA, and Habila JD. Chemical investigation and antioxidant activity of fractions of Lannea humilis (Oliv.) Engl. JOTCSA. 2017; 4(2): 87-96.

Submitted: January 27, 2017. Revised: March 10, 2017. Accepted: March 27, 2017.

DOI: $10.18596 /$ jotcsa.288249.

*Corresponding author. E-mail: adajiileileile@gmail.com 


\section{INTRODUCTION}

Antioxidants have various applications because of their different parts in reducing destructive impacts of oxidative stress (1). Antioxidant agents respond by free radical or molecular oxygen extinguishing, being able to either postpone or restrain oxidation which happens under the influence of molecular oxygen species. Antioxidants are in charge of the shielding mechanism of the living being against the pathologies connected with the assault of free radicals, in this manner the consumption of plant related antioxidants is responsible for the avoidance of degenerative ailments brought about by oxidative anxiety, for example, Cancer, Parkinson, Alzheimer, or Atherosclerosis [2]. Free radicals are broadly accepted to facilitate the development of a few ailments by bringing about oxidative anxiety and eventually oxidative harm which are reasons for some pathological diseases (3-6). Researchers recommend that if oxidative harm could be observed to be in charge of the continually increasing occurrence of different neurotic conditions, then quest for normal cancer prevention agents that could prevent the oxidation of free radicals would be scientifically valuable $(7,8)$. The phytochemicals in plants, green tea for example, have antioxidants properties used to enhance and give security against numerous ailments connected with reactive oxygen species (ROS, for instance, tumor and neurodegenerative diseases) $(9,10)$. It belongs to the family Anacardiaceae, it a deciduous bush growing up to 3 meters tall, at times turning into a tree with a level or spreading crown. A decoction of the stem bark of this plant is utilized in the treatment of sickness, hack, bodily torments intense looseness of the bowels, cholera, and asthma (11). 


\section{MATERIALS AND METHODS}

\section{Collection and identification of plant}

The fresh stem bark of $L$. humilis was collected from Otukpo, Benue state, Nigeria in January 2015. The plant was identified with a voucher specimen number 3231 by Mal. S. Namadi at the Herbarium section, Department of Botany, Faculty of Life Science, Ahmadu Bello University, Samaru, Kaduna State, Nigeria.

\section{Extraction of plant materials}

The stem bark of $L$. humilis were air-dried at room temperature $\left(27^{\circ} \mathrm{C}\right)$ for 2 weeks, after which it was grinded to a uniform powder. The crude methanol extract was prepared by soaking $100 \mathrm{~g}$ of the dry powdered plant materials in $1 \mathrm{~L}$ of methanol at ambient temperature for $48 \mathrm{~h}$. The extract was filtered after $48 \mathrm{hrs}$ and was concentrated using a rotary evaporator with the water bath set at $40^{\circ} \mathrm{C}$. A portion of this extract was reconstituted in water to yield a water-soluble fraction and water-insoluble fraction. The two fractions were subsequently partitioned successively and exhaustively using hexane and ethyl acetate, which were then concentrated using a rotary evaporator.

\section{Phytochemical screening}

The extract and the fractions were qualitatively examined for phytochemicals following standard procedures $(12,13)$.

\section{Determination of antioxidant activity}

The radical scavenging activities of the extract against 2,2-diphenyl-1-picrylhydrazyl (DDPH) radical were determined using UV spectrophotometer at $515 \mathrm{~nm}$. Radical scavenging activity was measured by a slightly modified method previously described (14). The following concentrations of the extracts were prepared, 15, 30, 60, 120, $240 \mu \mathrm{g} \cdot \mathrm{mL}^{-1}$ in methanol. 
Vitamin C was used as the antioxidant standard at concentrations of $15,30,60,120,240$ $\mu \mathrm{g} \cdot \mathrm{mL}^{-1} .1 \mathrm{~mL}$ of the extract was placed in a test tube, and $1 \mathrm{~mL}$ of $0.3 \mathrm{mM}$ methanolic solution of DPPH added. A blank solution was prepared containing the same amount of methanol and DPPH. The radical scavenging activity was calculated using the following formula:

$$
\% \text { radical scavenging activity }=\frac{\text { Absorbance of control }- \text { Absorbance of sample }}{\text { Absorbance of control }} \times 100
$$

\section{RESULTS AND DISCUSSION}

Table 1: Phytochemical Screening of the Extracts of the Stem Bark of L. humilis

\begin{tabular}{llcc}
\hline Metabolites & LHH & LHE & EHM \\
\hline Terpenes & + & + & + \\
Sterols & + & + & + \\
Carbohydrates & - & - & + \\
Glycosides & - & - & + \\
Tannins & - & + & + \\
Flavonoids & - & + & + \\
Anthraquinones & - & - & + \\
Alkaloids & - & + & +
\end{tabular}

Key: + =present, - = absent, LHH: hexane fraction, LHE: ethyl acetate fraction, LHM: methanol fraction.

The result of the phytochemical screening of the fractions of the stem bark of $L$. humilis is reported in Table 1. The phytochemical examination of the hexane, ethyl acetate and methanol extracts of the stem bark extract of $L$. humilis has uncovered the availability of some bioactive principles. Steroids and terpenes were available in the hexane, ethyl acetate, and methanol fractions, while tannins, flavonoids, and alkaloids were available in the ethyl acetate and methanol fractions. Carbohydrate and saponins were available in the methanol 
Ilemona, Gbekele-Oluwa, Ojo, and Habila. JOTCSA. 2017; 4(2): 563-572.

fraction. Anthraquinones were absent in all the fractions. The availability of these metabolites has proven earlier report that various plants in same family with $L$. humilis likewise have a large portion of the phytochemicals as observed in this plant (11). The presence of flavonoids, carbohydrate and cardiac glycosides in the ethyl acetate and methanol extract is not unexpected as the majority of these constituents are basically polar in nature. Flavonoids which are normal cancer prevention agent are acquired chiefly from plants, and are utilized for the treatment of degenerative infections (15). The inconceivable number of these chemical constituents in the stembark of $L$. humilis, some of which are be bioactive legitimizes the ethnomedicinal uses of this plant in the treatment of diseases.

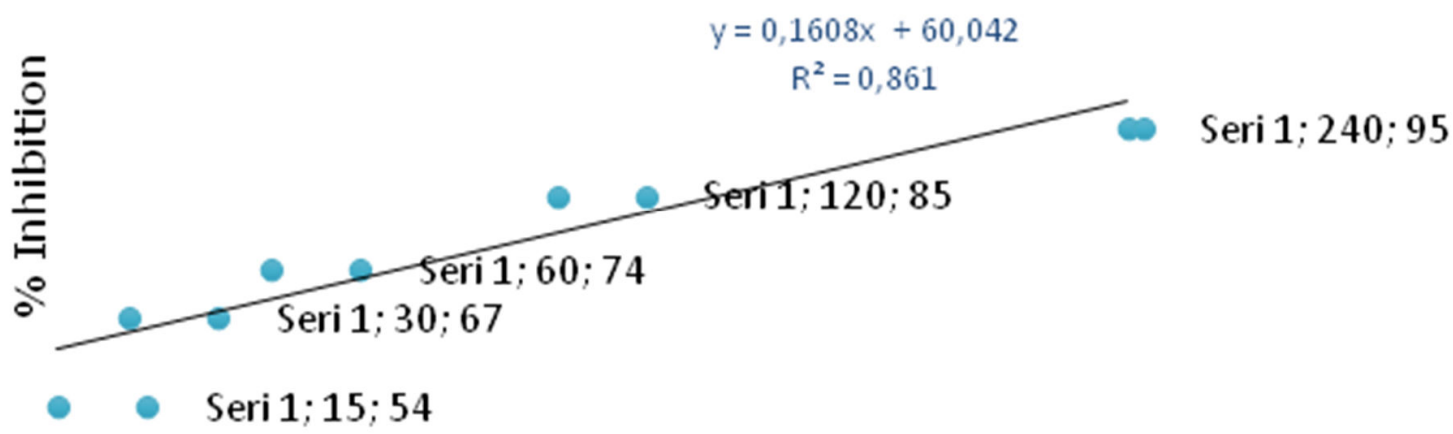

\section{Concentration $\left(\mu \mathrm{g} \cdot \mathrm{mL}^{-1}\right)$}

Figure 1: DDPH Scavenging Activity of the Hexane Extract of Lannea humilis. 


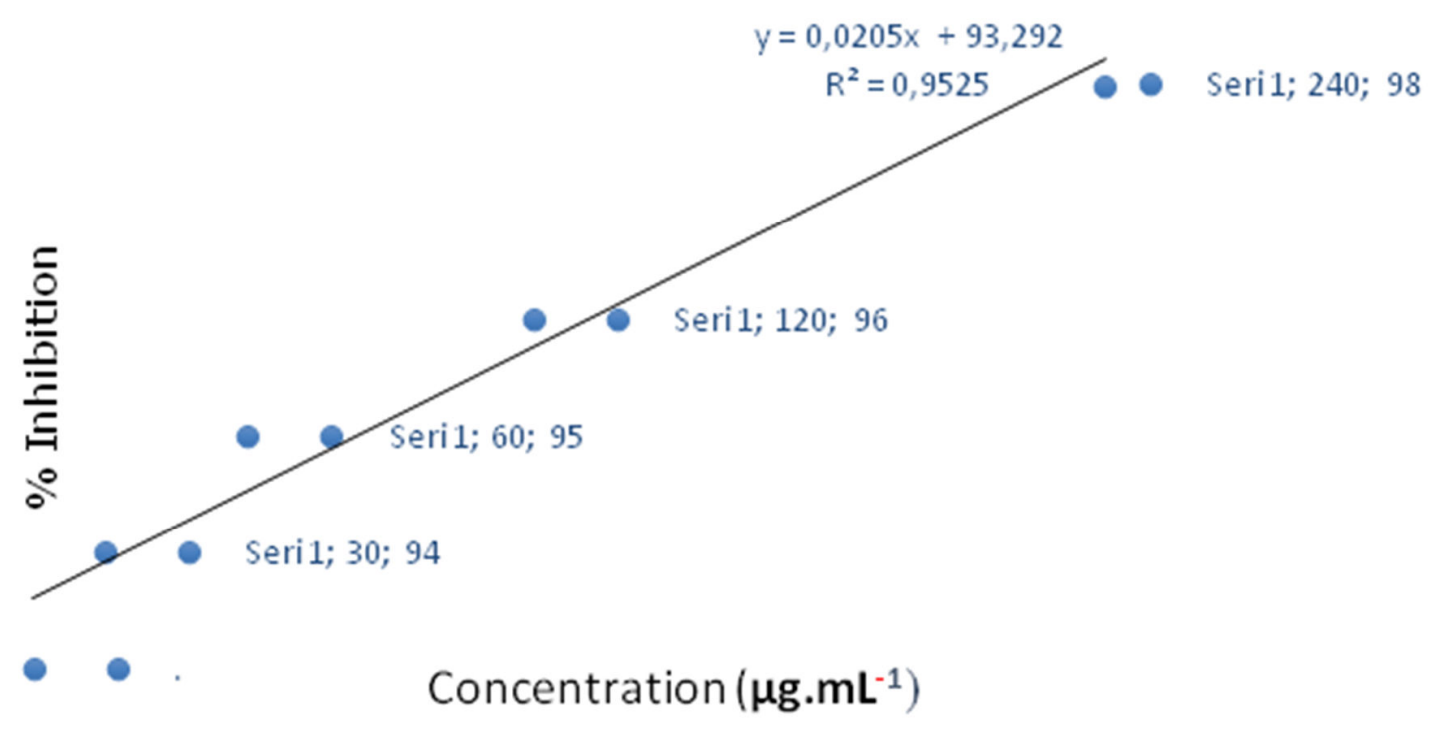

Figure 2: DDPH Scavenging Activity of the Ethyl acetate Extract of Lannea humilis.

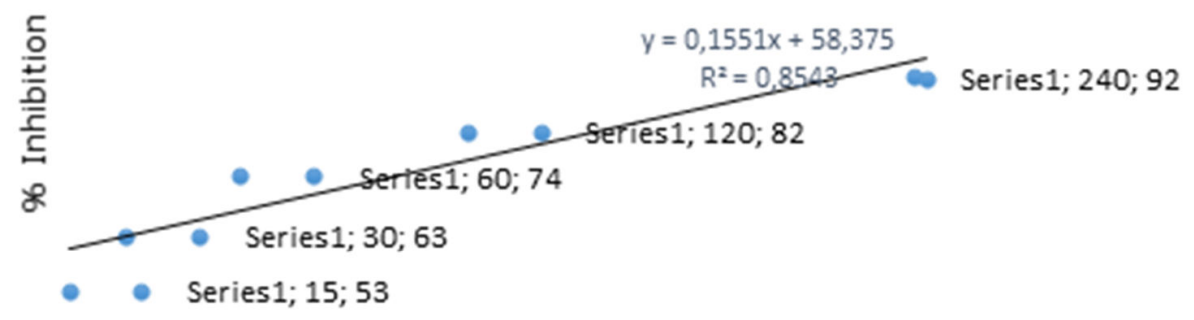

\section{Concentration $\left(\mu \mathrm{g} \cdot \mathrm{mL}^{-1}\right)$}

Figure 3: DDPH Scavenging Activity of the Methanol Extract of Lannea humilis. 


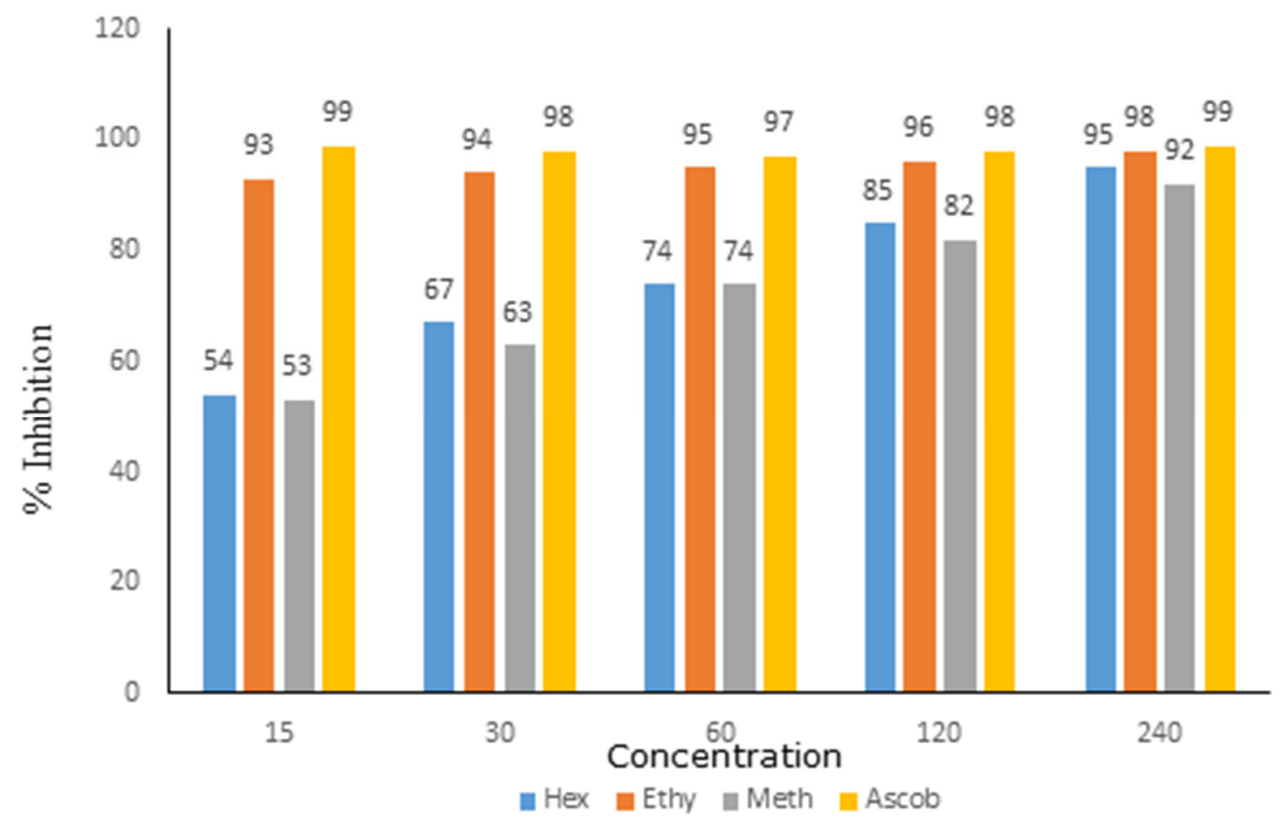

Figure 4: Inhibition of DPPH by the Hexane, Ethyl acetate and Methanol Extracts of Lannea humilis in Comparison with Ascorbic acid $\left(\mu \mathrm{g} \cdot \mathrm{mL}^{-1}\right)$.

The antioxidant capacity of the hexane, ethyl acetate and methanol fraction of L. humilis to repress and extinguish free radicals and responsive oxygen species was analyzed in this study. DPPH radical has been utilized widely as a free radical to test the reductive capacity of fractions or chemicals as free radical scavengers or hydrogen contributors and to assess the antioxidant activity of plant fractions $(16,17)$. Antioxidants respond to DPPH $\bullet$ by giving electron or hydrogen particle, in this way reducing it to 1,1-diphenyl-2-hydrazine (DPPH-H) or a substitute practically equivalent to hydrazine. The profound violet shade of DPPH at most extreme absorption of $515 \mathrm{~nm}$ is changed to light yellow, colorless or bleached product, resulting in decrease in absorption $(18,19)$. The hexane extract of $L$. humilis displayed noteworthy antioxidant activity of $95 \%$ at $240 \mu \mathrm{g} \cdot \mathrm{mL}^{-1}$ (Figure. 1) and compared well with the standard ascorbic acid. In like manner, the test technique for DPPH scavenging action connects amazingly with the adjustments in the different concentration of the hexane utilized, 
with relationship coefficients $\left(r^{2}\right)$ of 0.861 . This infers that the DPPH scavenging activity of the extracts of this plant is concentration dependent as highest percentage inhibitions were observed at a corresponding highest concentration for all the extracts. The percentage inhibition created by the ethyl acetate extract was $98 \%$ at a concentration of $240 \mu \mathrm{g} \cdot \mathrm{mL}^{-1}$, while that of the methanol fraction of $L$. humilis was $92 \%$ at the same concentration as shown in Figure 2 and 3. The three fractions of this plant showed comparable antioxidant activity with the positive standard antioxidant agent, ascorbic acid (Figure 4). These results show that the fractions of this plant can scavenge free radicals. The scavenging activity of the plant fractions on DPPH has been shown to be related to the phenolic concentration of the fractions $(20,21,22)$, which is accepted to add to their electron exchange/hydrogen giving capacity. It could hence be inferred that flavonoids contents of the fractions of this plant as revealed in the phytochemical screening results is responsible for stabilizing radicals or scavenge their activities.

In conclusion, this result suggests that the phenolic compounds might be major contributors to the antioxidative activities of the stem bark L. humilis. Further efforts are underway to isolate and identify the active phenolic compounds from the plant.

\section{REFERENCES}

1. Omar UM, Shorbaji AM, Arrait EM, Al Agha TD, Al-Marzouki HF, Al Doghaither HA, et al. Comparative Study of the Antioxidant Activity of Two Popular Green Tea Beverages Available in the Local Market of Saudi Arabia. Natural Science. 2016;8(06):227.

2. Pisoschi AM, Negulescu GP. Methods for total antioxidant activity determination: a review. Biochemistry and Analytical Biochemistry. 2011;1(1):1-10.

3. El-Bahr SM. Biochemistry of free radicals and oxidative stress. Science international. 2013;1(5):111117.

4. Gan L, Johnson JA. Oxidative damage and the Nrf2-ARE pathway in neurodegenerative diseases. Biochimica et Biophysica Acta (BBA)-Molecular Basis of Disease. 2014;1842(8):1208-1218.

5. Somanah J, Bourdon E, Rondeau P, Bahorun T, Aruoma OI. Relationship between fermented papaya preparation supplementation, erythrocyte integrity and antioxidant status in pre-diabetics. Food and Chemical Toxicology. 2014;65:12-17. 
6. Wong BX, Duce JA. The iron regulatory capability of the major protein participants in prevalent neurodegenerative disorders. The Importance Of Iron In Pathophysiologic Conditions. 2015;368.

7. Halliwell B. Role of free radicals in the neurodegenerative diseases. Drugs \& aging. $2001 ; 18(9): 685-$ 716.

8. Liu Q, Raina AK, Smith MA, Sayre LM, Perry G. Hydroxynonenal, toxic carbonyls, and Alzheimer disease. Molecular aspects of medicine. 2003;24(4):305-313.

9. Tran J, others. Green tea: a potential alternative anti-infectious agent catechins and viral infections. Advances in Anthropology. 2013;3(04):198.

10. Lobo V, Patil A, Phatak A, Chandra N, others. Free radicals, antioxidants and functional foods: Impact on human health. Pharmacognosy reviews. 2010;4(8):118.

11. Burkill H. The useful plants of West Africa (tropical). Royal Botanic Gardens, Kew. 1985;319.

12. Sofowora A. Medicinal plants and traditional medicine in Africa. 1982;

13. Trease GE, Evans WC. Pharmacognosy. 1989. Bailliere Tindall, London. :45-50.

14. Mensor LL, Menezes FS, Leitão GG, Reis AS, Santos TC dos, Coube CS, et al. Screening of Brazilian plant extracts for antioxidant activity by the use of DPPH free radical method. Phytotherapy research. $2001 ; 15(2): 127-130$.

15. Ali SS, Kasoju N, Luthra A, Singh A, Sharanabasava H, Sahu A, et al. Indian medicinal herbs as sources of antioxidants. Food Research International. 2008;41(1):1-15.

16. Da Porto C, Calligaris S, Celotti E, Nicoli MC. Antiradical properties of commercial cognacs assessed by the DPPH• test. Journal of Agricultural and Food Chemistry. 2000;48(9):4241-4245.

17. Manian R, Anusuya N, Siddhuraju P, Manian S. The antioxidant activity and free radical scavenging potential of two different solvent extracts of Camellia sinensis (L.) O. Kuntz, Ficus bengalensis L. and Ficus racemosa L. Food Chemistry. 2008;107(3):1000-1007.

18. Miliauskas G, Venskutonis $P$, Van Beek T. Screening of radical scavenging activity of some medicinal and aromatic plant extracts. Food chemistry. 2004;85(2):231-237.

19. Köksal E, Gülçin İ, Beyza S, Sarikaya Ö, Bursal E. In vitro antioxidant activity of silymarin. Journal of enzyme inhibition and medicinal chemistry. 2009;24(2):395-405.

20. Akinmoladun AC, Obuotor EM, Farombi EO. Evaluation of antioxidant and free radical scavenging capacities of some Nigerian indigenous medicinal plants. Journal of Medicinal Food. 2010;13(2):444451.

21. Sen S, De B, Devanna N, Chakraborty R. Total phenolic, total flavonoid content, and antioxidant capacity of the leaves of Meyna spinosa Roxb., an Indian medicinal plant. Chinese journal of natural medicines. 2013;11(2):149-157.

22. Das $N$, Islam ME, Jahan N, Islam MS, Khan A, Islam MR, et al. Antioxidant activities of ethanol extracts and fractions of Crescentia cujete leaves and stem bark and the involvement of phenolic compounds. BMC complementary and alternative medicine. $2014 ; 14(1): 45$. 
